\title{
Supporting Information \\ Detection and Evaluation of Lipid Classes and other Hydrophobic Compounds using a Laser Desorption/Plasma Ionization Interface
}

\author{
Alexander Knodel ${ }^{\dagger}$, Daniel Foest ${ }^{\dagger}$, Sebastian Brandt ${ }^{\dagger}$, Norman Ahlmann ${ }^{\dagger}$, Ulrich Marggraf ${ }^{\dagger}$, Bienvenida \\ Gilbert-López ${ }^{\S}$, Joachim Franzke ${ }^{\dagger, *}$ \\ 'Leibniz-Institut für Analytische Wissenschaften - ISAS - e.V., Bunsen-Kirchhoff-Straße 11, 44139 Dortmund, Germany \\ §Analytical Chemistry Research Group (FQM-323), Department of Physical and Analytical Chemistry, University of Jaén, Campus Las \\ Lagunillas, Edif. B-3, 23071 Jaén, Spain
}

\section{Supporting Information}

\section{Table of Contents}

Figure S1. Laser spot $\left(\lambda_{0}=450 \mathrm{~nm}\right)$ in focus, 1 Px equals $8 \mu \mathrm{m}$.

Figure S2. Laser spot $\left(\lambda_{0}=448 \mathrm{~nm}\right)$ in focus, 1 Px equals $8 \mu \mathrm{m}$.

Figure S3. Calibration curve of the laser diode current to applied laser power guided through optics.

Figure S4. Integrated ion intensities for different laser fluencies and compounds. $m_{\text {Sphingomyelin }}=0.50 \mu g, m_{\text {Ibuprofen }}=0.25 \mu$, $m_{\text {Oleic Acid }}=0.05 \mu \mathrm{g}, m_{\text {Cholesterol margarate }}=0.50 \mu \mathrm{g}, m_{\text {Liver Extract }}=1.3 \mu \mathrm{g}, m_{D L P C}=0.25 \mu \mathrm{g}$. Injection time is fixed at $5 \mathrm{~ms}$.

Figure S5. Positive ion mode mass spectra of DLPC. $m=250 \mathrm{ng}$.

Figure S6. Positive ion mode mass spectra of sphingomyelin. $m=250$ ng.

Figure S7. Positive ion mode mass spectra of caffeine and Ultramark $1621 \circledR(0.001 \%$, Calibration solution 88322 RE229094). $m_{\text {Coff }}=10$ ng.

Figure S8. Positive ion mode mass spectra of beta carotene. $m=50 \mathrm{ng}$.

Figure S9. Negative ion mode mass spectra of ibuprofen. $m=250 \mathrm{ng}$.

Figure S10. Positive ion mode mass spectra of ibuprofen. $m=250 \mathrm{ng}$.

Figure S11. Negative ion mode mass spectra of ketoprofen. $m=250 \mathrm{ng}$.

Figure S12. Positive ion mode mass spectra of ketoprofen. $m=250$ ng.

Figure S13. Substrate charges with plasma $(2.1 \mathrm{kV})$ on with increasing distance from the ion source, measured on the substrate.

\author{
Author Information \\ Corresponding Author \\ *Tel.: +49 (0)231 1392-174, FAX: +49 (0)231 1392-120, Mail: franzke@,isas.de
}




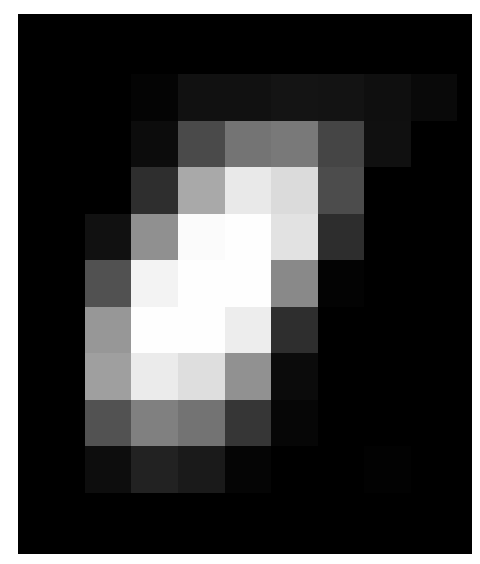

Figure S1. Laser spot $\left(\lambda_{0}=450 \mathrm{~nm}\right)$ in focus, 1 Px equals $8 \mu \mathrm{m}$.

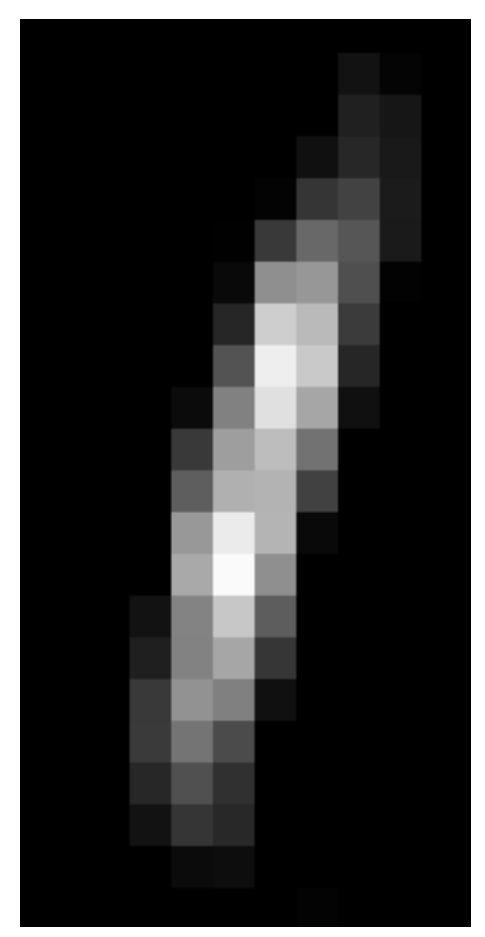

Figure S2. Laser spot $\left(\lambda_{0}=448 \mathrm{~nm}\right)$ in focus, 1 Px equals $8 \mu \mathrm{m}$. 


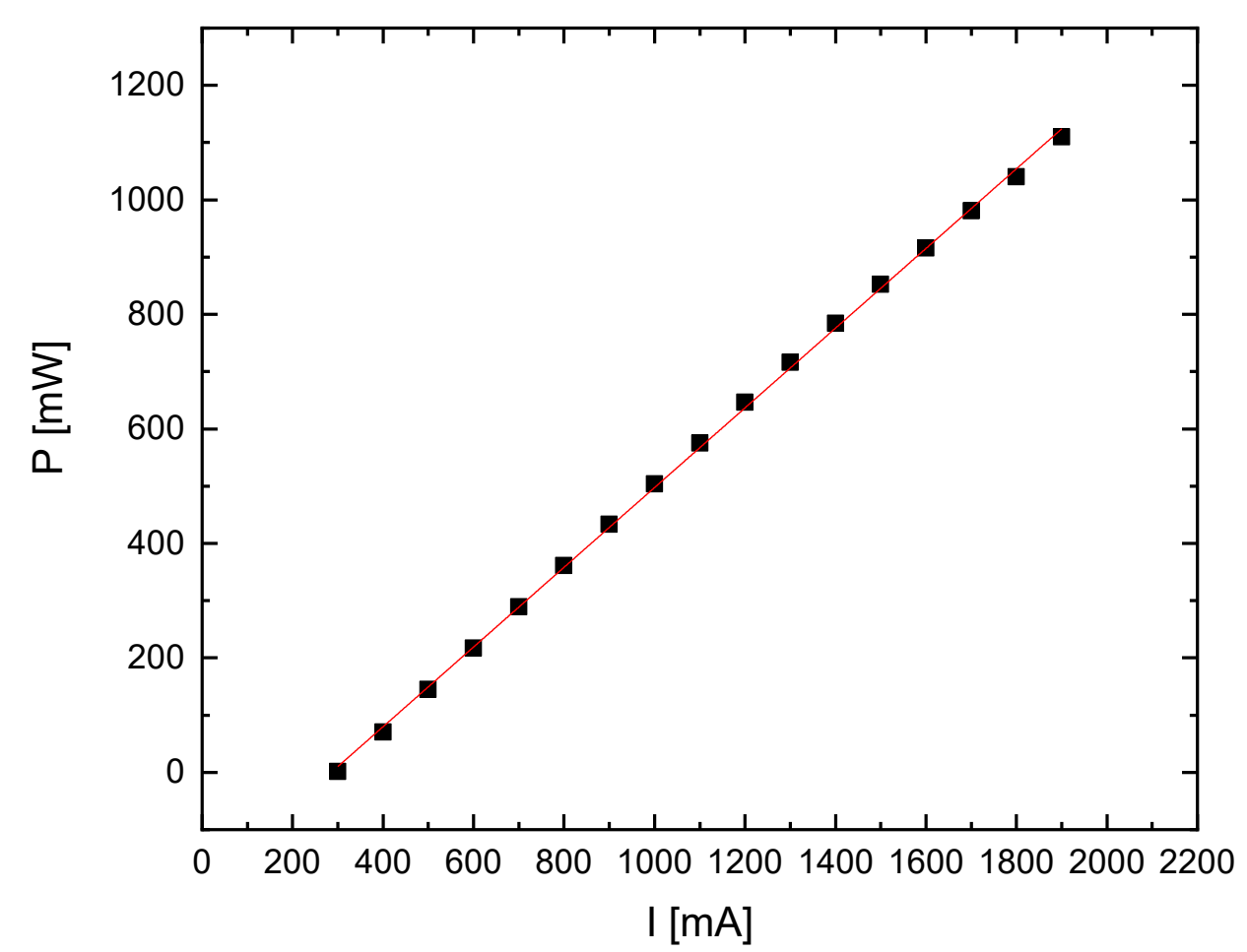

Figure S3. Calibration curve of the laser diode current to applied laser power guided through optics.

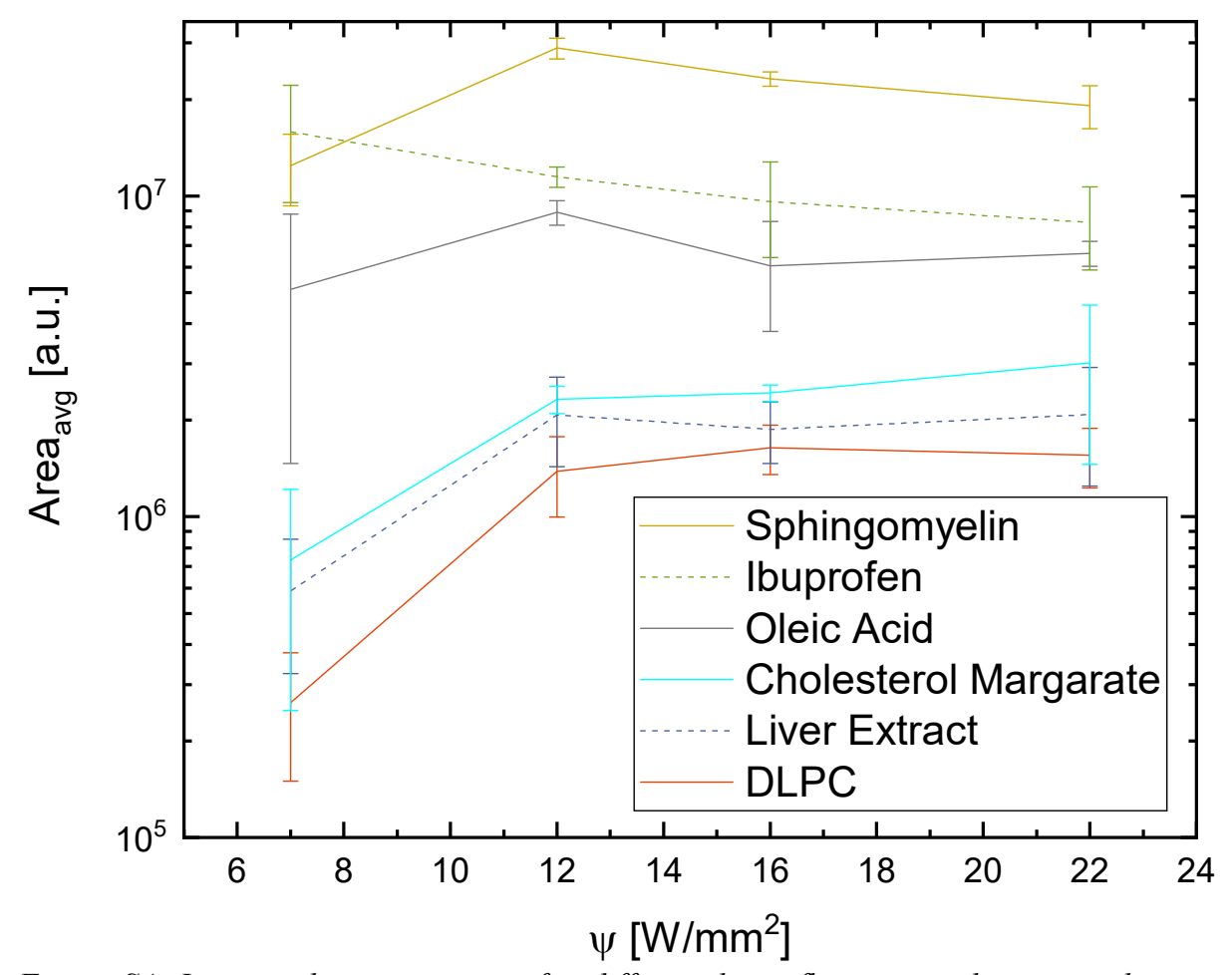

Figure S4. Integrated ion intensities for different laser fluencies and compounds. $m_{\text {Sphingomyelin }}=0.50 \mu g, m_{\text {Ibuprofen }}=0.25 \mu g$, $m_{\text {Oleic Acid }}=0.05 \mu \mathrm{g}, m_{\text {Cholesterol margarate }}=0.50 \mu \mathrm{g}, m_{\text {Liver Extract }}=1.3 \mu \mathrm{g}, m_{D L P C}=0.25 \mu \mathrm{g}$. Injection time is fixed at $5 \mathrm{~ms}$. 


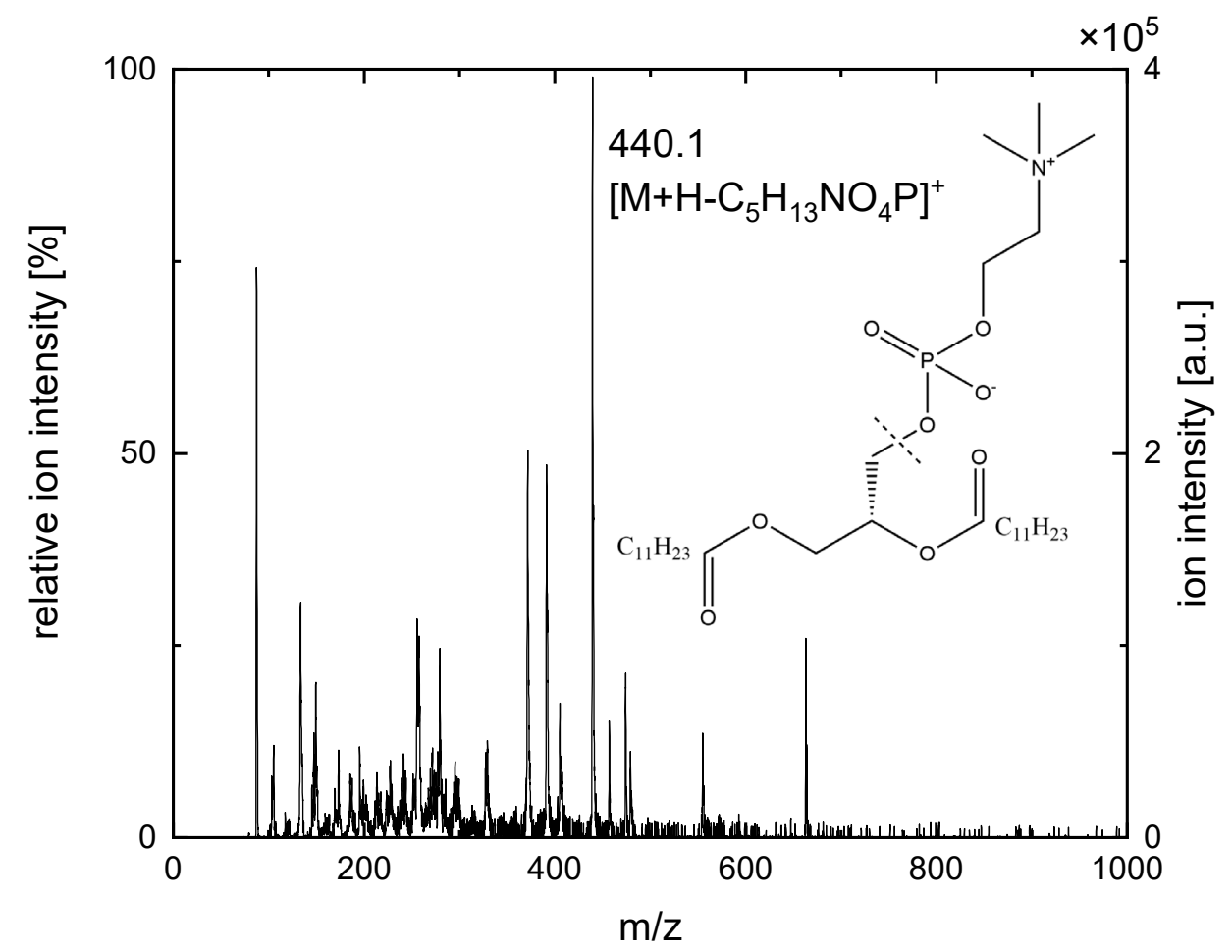

Figure S5. Positive ion mode mass spectra of DLPC. $m=250 \mathrm{ng}$.

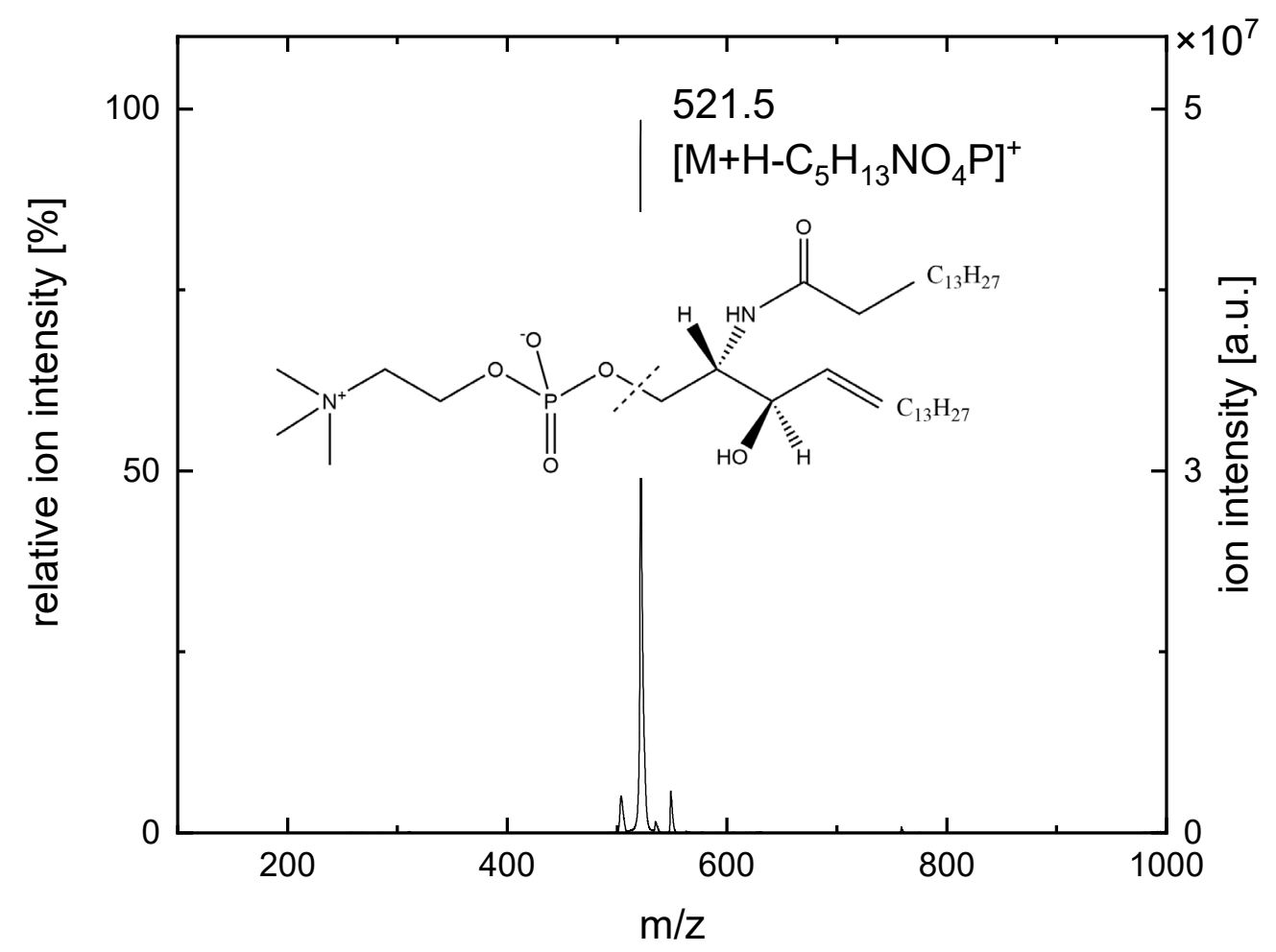

Figure S6. Positive ion mode mass spectra of sphingomyelin. $m=250$ ng. 


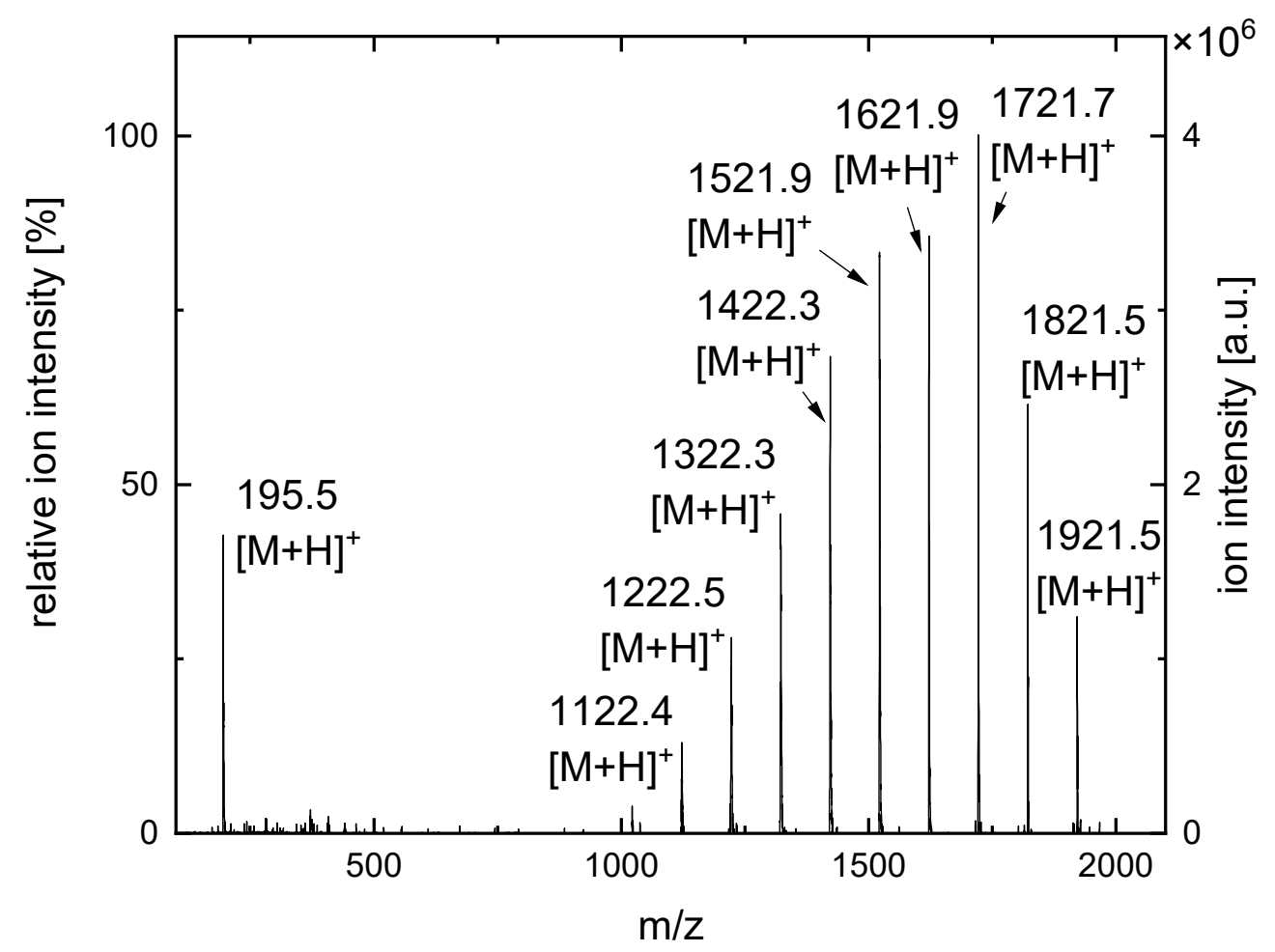

Figure S7. Positive ion mode mass spectra of caffeine and Ultramark 1621®(0.001\%, Calibration solution 88322 RE229094). $m_{\text {Coff }}=10$ ng.

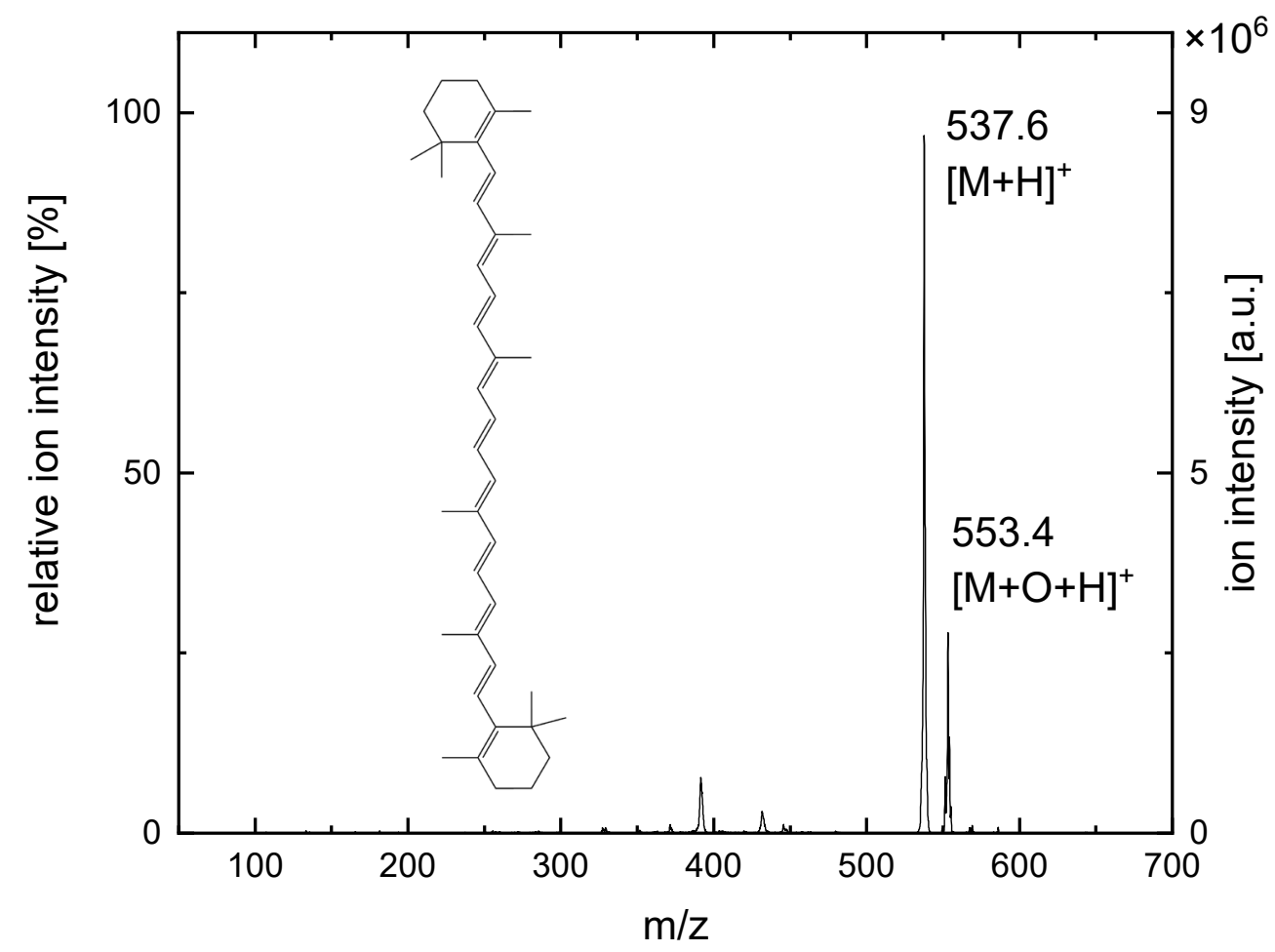

Figure S8. Positive ion mode mass spectra of beta carotene. $m=50 n g$. 


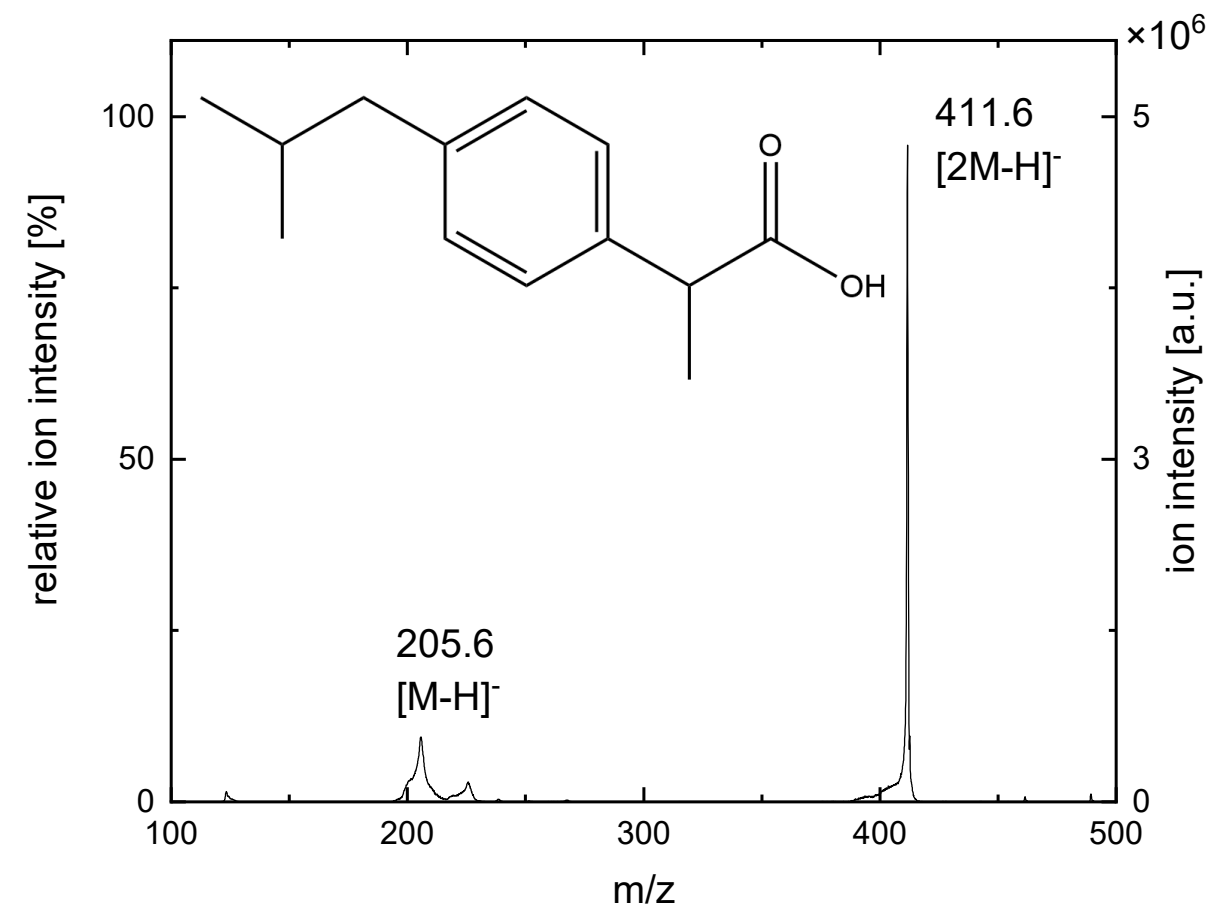

Figure S9. Negative ion mode mass spectra of ibuprofen. $m=250$ ng.

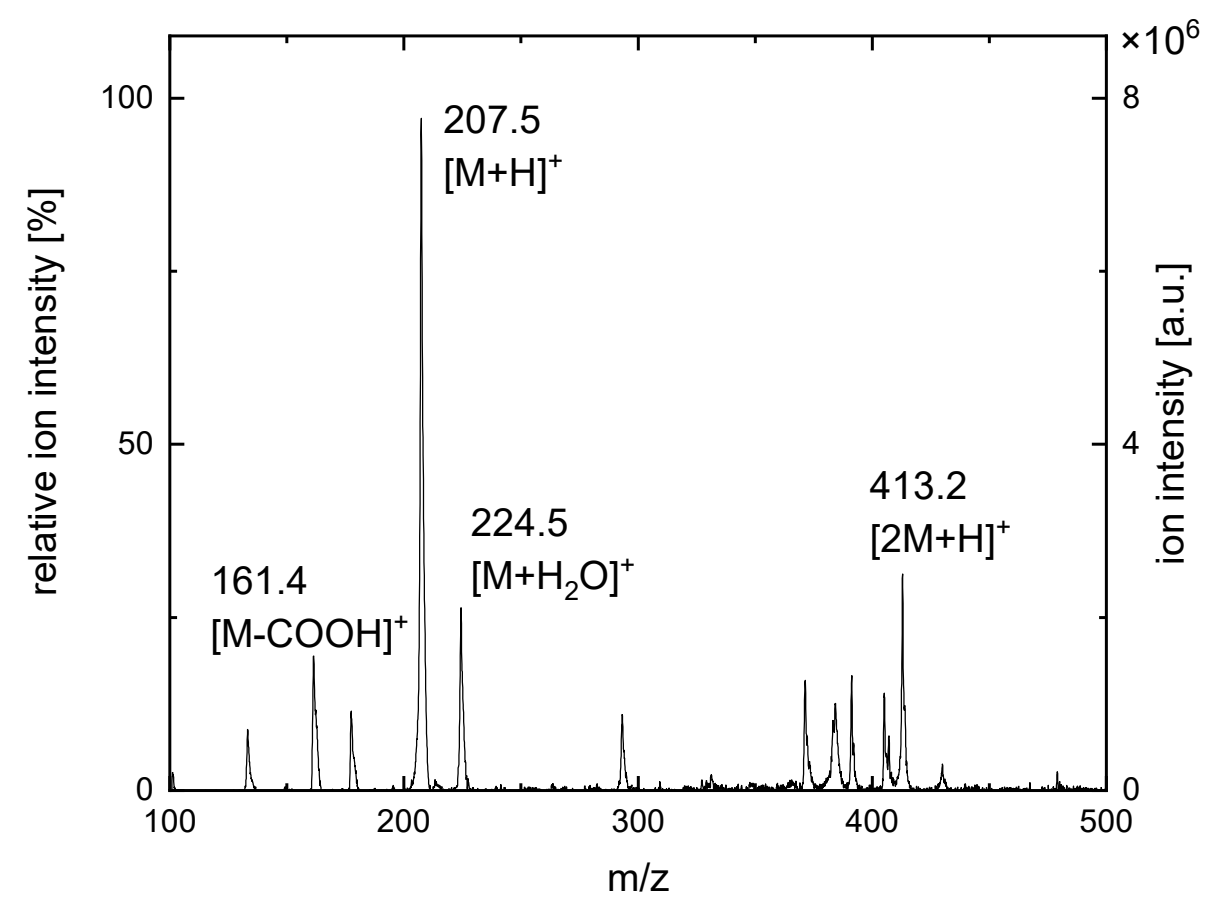

Figure S10. Positive ion mode mass spectra of ibuprofen. $m=250$ ng. 


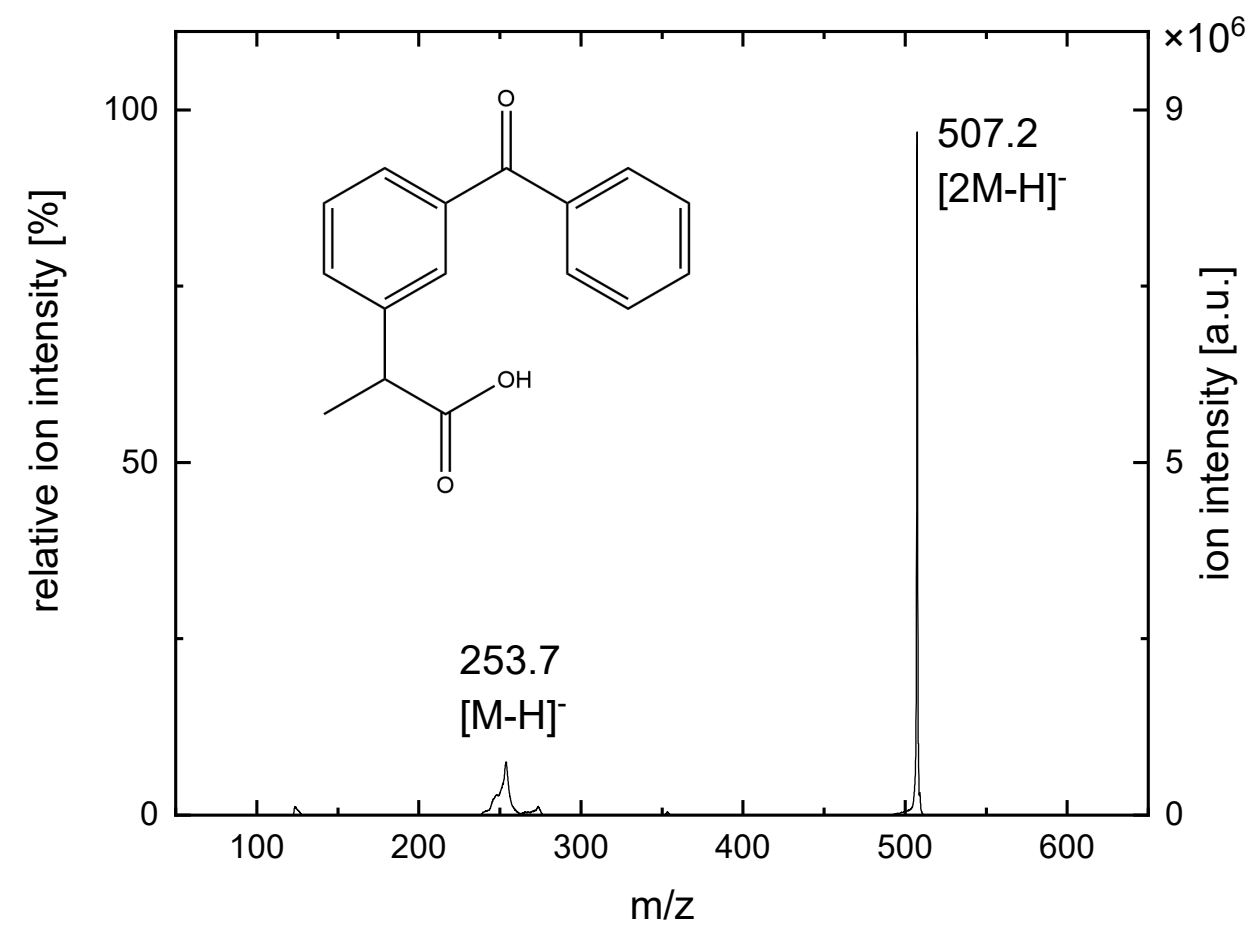

Figure S11. Negative ion mode mass spectra of ketoprofen. $m=250 \mathrm{ng}$.

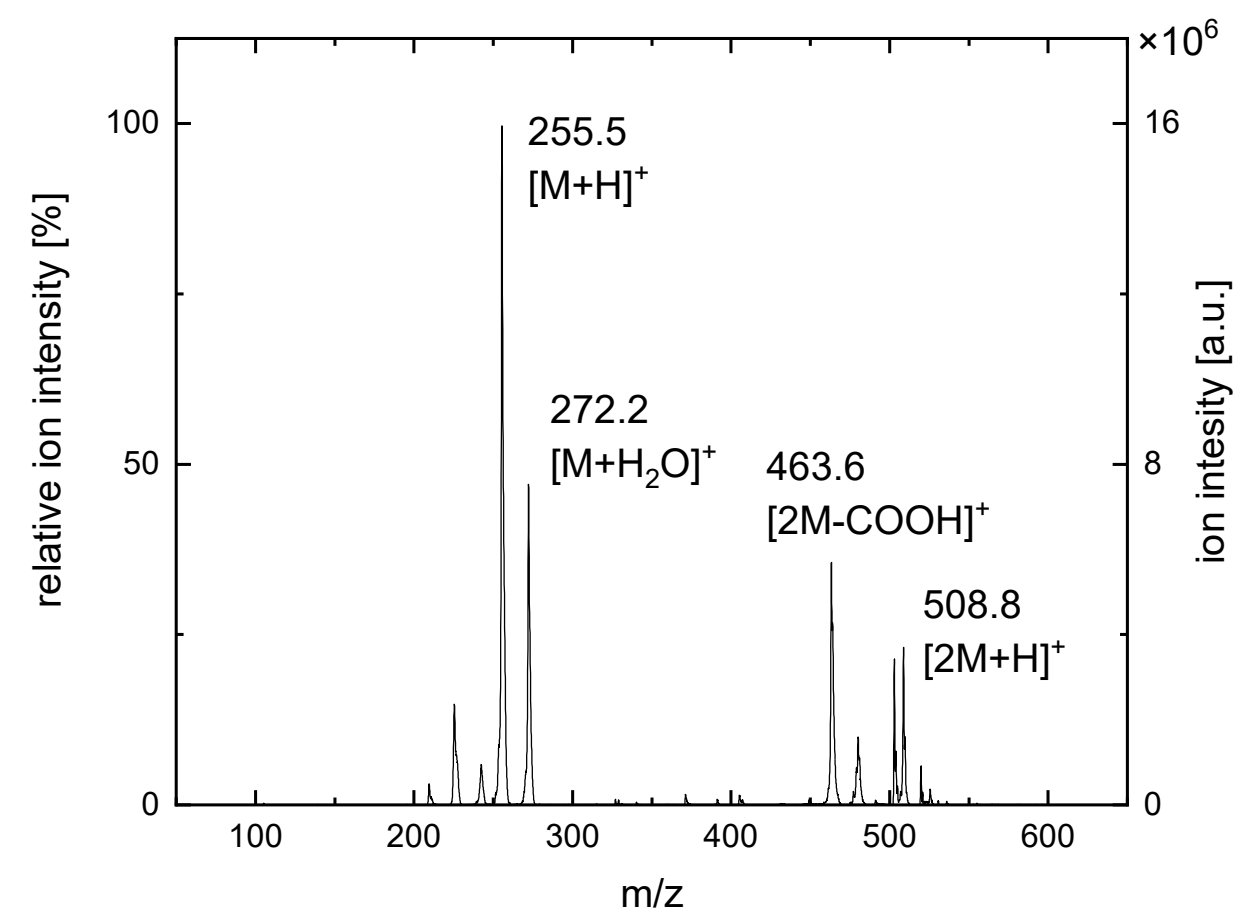

Figure S12. Positive ion mode mass spectra of ketoprofen. $m=250$ ng. 


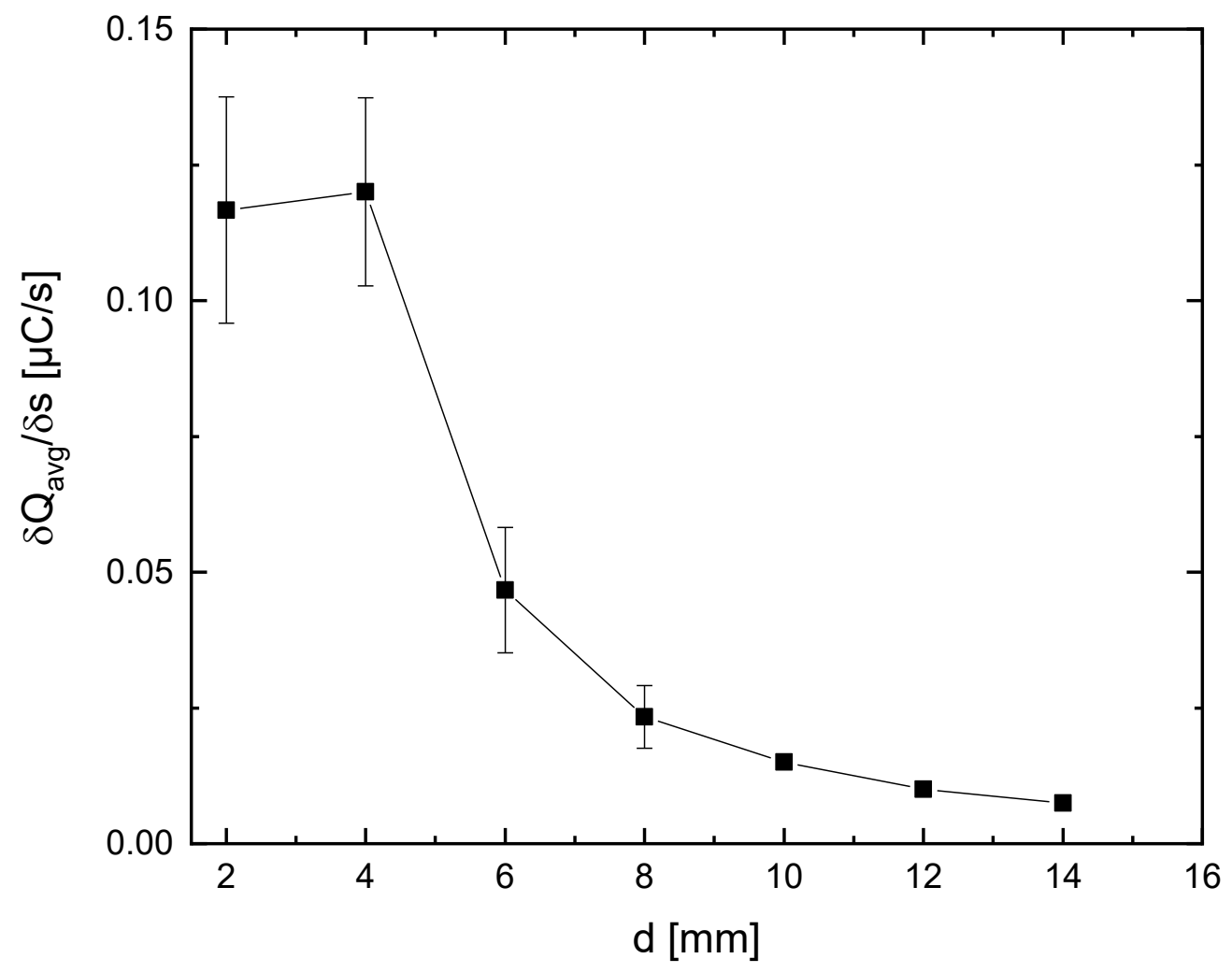

Figure S13. Substrate charges with plasma $(2.1 \mathrm{kV})$ on with increasing distance from the ion source, measured on the substrate. 